\title{
BMJ Open E-cigarettes, a safer alternative for teenagers? A UK focus group study of teenagers' views
}

\author{
Shona Hilton, ${ }^{1}$ Heide Weishaar, ${ }^{1}$ Helen Sweeting, ${ }^{1}$ Filippo Trevisan, ${ }^{2}$ \\ Srinivasa Vittal Katikireddi ${ }^{1}$
}

To cite: Hilton S, Weishaar $\mathrm{H}$, Sweeting $\mathrm{H}$, et al. Ecigarettes, a safer alternative for teenagers? A UK focus group study of teenagers' views. BMJ Open 2016;6: e013271. doi:10.1136/ bmjopen-2016-013271

- Prepublication history for this paper is available online. To view these files please visit the journal online (http://dx.doi.org/10.1136/ bmjopen-2016-013271)

Received 30 June 2016 Revised 12 October 2016 Accepted 1 November 2016

\section{CrossMark}

${ }^{1} \mathrm{MRC} / \mathrm{CSO}$ Social and Public Health Sciences Unit, University of Glasgow, Scotland, UK

${ }^{2}$ American University, School of Communication,

Washington, District of Columbia, USA

Correspondence to Dr Shona Hilton; shona. hilton@glasgow.ac.uk

\section{ABSTRACT}

Objective: Concerns exist that e-cigarettes may be a gateway to traditional cigarettes and/or (re)normalise teenage smoking. This qualitative study explores how teenagers in the UK currently perceive e-cigarettes and how and why they do or do not use them.

Design: 16 focus groups were conducted across the UK between November 2014 and February 2015, with 83 teenagers aged 14-17. All discussions were digitally recorded, transcribed verbatim, imported into NVivo 10 and thematically analysed.

Results: Teenagers generally agreed that e-cigarettes are useful products for smokers, including teenage smokers, to quit or reduce traditional cigarette use. Concerns were expressed about lack of information on their precise ingredients and any unknown risks for users and bystanders. However, teenagers typically viewed e-cigarettes as substantially less harmful than traditional cigarettes. They perceived e-cigarettes as attractive, with products described as 'fun' and having 'great flavourings'. Seeing websites or social media featuring e-cigarettes, especially YouTube 'vaping tricks', prompted some experimentation and imitation. E-cigarettes were used in a variety of situations, including at parties or when they could not smoke traditional cigarettes. A very few participants suggested covert use was a possibility and that e-cigarettes might help maintain a fledgling nicotine habit.

Conclusions: Teenagers support the use of e-cigarettes as smoking cessation aids for established adult smokers. However, they engage with these products differently from adults, with the novel hypothesis that covert use could potentially reinforce traditional cigarette smoking requiring further investigation. Policy responses should more clearly meet the needs of young people, as well as helping established adult smokers.

\section{INTRODUCTION}

Electronic nicotine delivery systems (e-cigarettes) have become increasingly popular. ${ }^{1-3}$ Evidence on their potential benefits and harms is limited, and the views of public health researchers and advocates are divided, ${ }^{4-7}$ with

\section{Strengths and limitations of this study}

Understanding how teenagers perceive and use e-cigarettes is a research priority, given the potential lifelong consequences of behaviours established at this age, but little qualitative research has been conducted.

- This study provides one of the first indepth explorations of teenagers' lived experiences and perceptions of e-cigarettes.

- In consideration of the gateway theory, it is worth noting that this sample is not representative of British youth and the sample size did not allow detailed analyses of differences moving into smoking or opinions with regard to smoking status, e-cigarette use and socioeconomic variables. To what extent the experiences and perceptions of UK youth differ from those of young people in other countries remains to be explored.

controversial academic and public debates about e-cigarettes escalating recently. Proponents argue that e-cigarettes are $95 \%$ less harmful than tobacco, ${ }^{89}$ and useful adjuncts to help smokers quit; ${ }^{10-12}$ opponents fear they may encourage tobacco smoking uptake and maintenance, especially among teenagers. ${ }^{6}$ 13-17

Concerns that e-cigarettes may encourage a transition into tobacco smoking and that they may (re-)normalise smoking behaviours lie at the centre of the debate about their possible harms for teenagers. ${ }^{6}$ 13-17 Fears also exist that tobacco producers may use ecigarettes to influence public health policy and as a marketing opportunity to target young people, a group with high proclivity towards risky behaviours. ${ }^{18-20}$ As such, there is a growing need for indepth research on young people's perspectives on e-cigarettes to ensure responsive tobacco control policy aimed at young people. A recent systematic review of public awareness, use, reactions and beliefs about e-cigarettes found most relevant research focuses on the US context and investigates perceptions of e-cigarettes 
among adult tobacco smokers. ${ }^{21}$ Research which uses qualitative methods to explore how e-cigarettes are perceived by different population groups is particularly rare, with only a small number of studies focusing on young people's perceptions and use of e-cigarettes. ${ }^{22}$ Understanding how teenagers perceive and use e-cigarettes is a research priority, given most adult smokers start at this point in the life course. ${ }^{23}{ }^{24}$ This UK-based study therefore sought to qualitatively explore teenagers' perceptions of e-cigarettes and how and why they used them at a time when the regulation of e-cigarettes was high on the political agenda.

\section{METHODS}

Sixteen focus groups were conducted (November 2014 to February 2015), 11 in Scotland and 5 in England. Friendship groups of 4-7 participants were used to facilitate indepth insights and promote participant interaction. Purposive sampling was used to recruit a diverse range of teenagers in terms of socioeconomic background, gender, users/non-users of traditional cigarettes and/or e-cigarettes. To ensure the inclusion of enough participants with experiences of smoking or/and ecigarette use, half of the groups were recruited from more socioeconomically deprived areas also associated with higher uptake of smoking. All the participants were recruited from small local community groups, with 2 groups being recruited directly by researchers and the other 14 groups being recruited through youth leaders/ organisers handing out information. Participants were each given $£ 20$ vouchers to cover travel expenses and as appreciation for their time. The study and all its documentation obtained ethical approval from the University of Glasgow, College of Social Sciences. Informed written consent was obtained from every participant and one of their respective parents or guardians prior to taking part in the group discussion.

At the start of each group, participants completed a brief questionnaire which included fixed-choice questions, adapted from the Scottish Schools Adolescent Lifestyles and Substance Use Survey about their use of traditional cigarettes and e-cigarettes ('do you smoke cigarettes/use an e-cigarette at all nowadays', and 'which statement describes you best': never tried/used, not even a puff or two/not even once; once had a puff or two/once or twice tried, but never smoke/use now; do sometimes smoke/use). ${ }^{25}$ While such categorisations, which we describe here as 'never', 'tried' and 'current', may not exactly match young people's own smoking identity, they are indicative of the categories. ${ }^{26}$ These was complete agreement in respect of reporting current smoking and sometimes smoking and only one discrepancy in respect of reporting current e-cigarette use and sometimes using e-cigarettes (one 'current' user reported having tried once or twice, coded as 'tried').

A topic guide, based on past literature and pilot work, explored themes including: knowledge and understandings of e-cigarettes; beliefs about potential benefits and harms of e-cigarettes; and experiences of ecigarette use. Promotional advertising materials (posters, still images from television and online adverts) were used to help stimulate discussion. All discussions were facilitated by the same experienced qualitative researcher (FT), lasted 40-70 $\mathrm{min}$, were digitally recorded (with participants' permission) and transcribed verbatim. Transcripts were checked against the recordings for accuracy, and participants identified and given pseudonyms. Each transcript was imported into NVivo 10, thematically coded and cross-checked by the research team for agreement about the codes. This approach ensured a rigorous method to develop agreement on coding, discuss common reasoning and identify ideas specific to certain subgroups or individuals, or related to the literature. Using Glaser's constant comparative approach to analysis, ${ }^{27}$ attention was paid to any deviant/contradictory cases and to group dynamics using the transcripts supplemented by field-note observations.

\section{RESULTS}

Eighty-three individuals aged 14-17 years participated (44 males, 39 females), representing diversity in sociodemographic characteristics and smoking-related behaviours (table 1). It is notable that all current e-cigarette users used nicotine in their e-cigarettes and were also current smokers. Around a third of all current smokers were current dual users, all but one current smoker had experience of e-cigarettes. The targeted approach to recruitment meant that only eight never smokers in the study had ever tried an electronic cigarette (table 2). Of those participants that had used e-cigarettes, they had either purchased them over the internet or been given them from other teenagers. While all of the teenagers were well aware of vape shops, none of them mentioned having used a vape shop themselves to purchase e-cigarettes.

Participants appeared highly engaged and eager to discuss e-cigarettes. When asked what influenced their opinions, the media were commonly cited, with social media sources such as Facebook, Twitter and YouTube specifically mentioned, alongside the internet and stories from families and friends. In many discussions, teenagers drew on first-hand experiences and observations of their social circles. There was general agreement that e-cigarettes were a beneficial product for long-term smokers who wanted to quit or cut down smoking. However, most of the discussions focused on their potential harms, with a particular emphasis on young people and children. Participants frequently questioned, challenged and amended each other's statements, reflecting high levels of openness and ambiguity about e-cigarettes.

This paper presents, in turn, the four most dominant themes: (1) perceptions of the potential harms of 
Table 1 Focus group location, participants and their cigarette smoking and e-cigarette use

\begin{tabular}{|c|c|c|c|c|}
\hline Location & Pseudonym & Age & $\begin{array}{l}\text { Cigarette } \\
\text { smoker }\end{array}$ & $\begin{array}{l}\text { E-cig } \\
\text { use }\end{array}$ \\
\hline Glasgow & James & 15 & Never & Never \\
\hline \multirow[t]{3}{*}{ SW Scotland } & Gerry & 14 & Never & Never \\
\hline & Chrissie & 14 & Never & Never \\
\hline & Janice & 15 & Never & Never \\
\hline Glasgow & Felicity & 16 & Never & Never \\
\hline \multirow[t]{3}{*}{ SW Scotland } & Donald & 16 & Never & Never \\
\hline & Mitchell & 16 & Never & Never \\
\hline & Louis & 16 & Tried & Never \\
\hline Glasgow & Thomas & 16 & Never & Never \\
\hline \multirow[t]{4}{*}{ SW Scotland } & Alice & 17 & Tried & Tried \\
\hline & Joshua & 17 & Never & Never \\
\hline & Lachlan & 16 & Never & Never \\
\hline & David & 16 & Tried & Tried \\
\hline Glasgow & Robert & 14 & Never & Never \\
\hline \multirow[t]{4}{*}{ SW Scotland } & Liam & 14 & Never & Tried \\
\hline & Graham & 14 & Never & Never \\
\hline & Adrian & 15 & Never & Never \\
\hline & John & 14 & Tried & Never \\
\hline Glasgow & Maria & 16 & Never & Tried \\
\hline \multirow[t]{5}{*}{ SW Scotland } & Oliver & 16 & Never & Never \\
\hline & Allan & 17 & Never & Never \\
\hline & Clare & 17 & Tried & Tried \\
\hline & Jamie & 17 & Current & Never \\
\hline & Roslyn & 17 & Tried & Tried \\
\hline Edinburgh SE & lain & 17 & Current & Tried \\
\hline \multirow[t]{4}{*}{ Scotland } & Michael & 17 & Current & Tried \\
\hline & Stewart & 17 & Current & Current \\
\hline & Richard & 17 & Current & Tried \\
\hline & Hannah & 17 & Current & Tried \\
\hline Edinburgh SE & Hayley & 14 & Current & Tried \\
\hline \multirow[t]{6}{*}{ Scotland } & Lucy & 14 & Current & Tried \\
\hline & Jennifer & 14 & Current & Tried \\
\hline & Francis & 14 & Current & Tried \\
\hline & Judith & 14 & Current & Tried \\
\hline & Stuart & 15 & Never & Never \\
\hline & Niall & 14 & Current & Tried \\
\hline Edinburgh SE & Lorna & 16 & Current & Tried \\
\hline \multirow[t]{4}{*}{ Scotland } & Sharon & 16 & Current & Tried \\
\hline & Ben & 16 & Current & Tried \\
\hline & Wendy & 15 & Current & Tried \\
\hline & Christine & 17 & Current & Tried \\
\hline Edinburgh SE & Libby & 16 & Current & Tried \\
\hline \multirow[t]{4}{*}{ Scotland } & Fergus & 17 & Current & Current \\
\hline & Isaac & 17 & Never & Never \\
\hline & Helen & 17 & Tried & Never \\
\hline & Matthew & 17 & Current & Tried \\
\hline Kirkcaldy SE & Caiomhe & 15 & Never & Never \\
\hline \multirow[t]{5}{*}{ Scotland } & Lauren & 16 & Never & Never \\
\hline & Timothy & 16 & Current & Tried \\
\hline & Danyul & 16 & Current & Current \\
\hline & Lesley & 17 & Tried & Never \\
\hline & Jonathan & 17 & Never & Never \\
\hline Kirkcaldy SE & Fiona & 16 & Current & Current \\
\hline \multirow[t]{3}{*}{ Scotland } & Scott & 17 & Current & Tried \\
\hline & Murray & 16 & Current & Current \\
\hline & Louisa & 16 & Current & Current \\
\hline
\end{tabular}

Table 1 Continued

\begin{tabular}{lllll}
\hline Location & Pseudonym & Age & $\begin{array}{l}\text { Cigarette } \\
\text { smoker }\end{array}$ & $\begin{array}{l}\text { E-cig } \\
\text { use }\end{array}$ \\
\hline & Ella & 16 & Current & Current \\
& Aisha & 14 & Current & Current \\
Greater & Maggie & 15 & Current & Current \\
Manchester & Rhyan & 17 & Tried & Tried \\
NW England & Elizabeth & 16 & Never & Never \\
& Katie & 15 & Never & Never \\
& Harriet & 17 & Never & Never \\
Greater & Jane & 16 & Never & Never \\
Manchester & Darnell & 14 & Never & Tried \\
NW England & George & 16 & Tried & Tried \\
& Emma & 17 & Tried & Tried \\
& Paul & 17 & Never & Tried \\
Merseyside & Finlay & 15 & Never & Never \\
NW England & Sara & 15 & Never & Never \\
& Steven & 14 & Never & Never \\
& Katherine & 14 & Never & Never \\
Newcastle & Fraser & 14 & Never & Tried \\
NE England & Susan & 15 & Never & Tried \\
& Karen & 17 & Tried & Tried \\
& Drew & 16 & Never & Tried \\
& Alex & 17 & Current & Tried \\
Newcastle NE & Rosie & 17 & Tried & Never \\
England & Carla & 14 & Tried & Tried \\
& Mairi & 15 & Never & Tried \\
& Gregor & 17 & Current & Current \\
& Henry & 14 & Never & Never \\
\hline \multirow{5}{*}{} & & & & \\
& & & &
\end{tabular}

e-cigarettes; (2) appeal of e-cigarettes to children and teenagers; (3) acknowledgement of e-cigarette experimentation, use and dual use among different user groups; (4) interplay between online and real-world experiences.

\section{Perceptions of the potential harms of e-cigarettes}

Potential health harms and unknown harmful ingredients were a common theme, spontaneously expressed in 12 focus groups. Conversations focused on the lack of clarity over e-cigarette composition and potential risks to users and bystanders, with an acknowledgement that this uncertainty arose from their relative novelty. In five groups, participants hypothesised that future research might show e-cigarettes to be more harmful than currently acknowledged. In one instance, this claim was underpinned by a direct comparison with changing evidence on tobacco and the resulting increasing public awareness of harm:

Robert "When original cigarettes came out they didnae know it was bad for you, they were actually encouraging you tae smoke." (14, never-smoker, never e-cigarettes)

Liam 'An' then so the same point is, and obviously everybody knows here that smoking's bad, like normal cigarettes." (14, never-smoker, tried e-cigarettes) 
Table 2 E-cigarette use according to cigarette smoking —numbers (column and row percentages)

\begin{tabular}{|c|c|c|c|c|c|c|c|c|c|c|c|c|}
\hline \multirow[b]{3}{*}{ Cigarette smoker } & \multicolumn{12}{|c|}{ E-cigarette use } \\
\hline & \multicolumn{3}{|c|}{ Never } & \multicolumn{3}{|c|}{ Tried } & \multicolumn{3}{|c|}{ Current } & \multicolumn{3}{|c|}{ Total } \\
\hline & $\mathbf{N}$ & (col \%) & (row \%) & $\mathbf{N}$ & (col \%) & (row \%) & $\overline{\mathbf{N}}$ & (col \%) & (row \%) & $\overline{\mathbf{N}}$ & (col \%) & (row \%) \\
\hline Never & 29 & (81) & (78) & 8 & (22) & (22) & 0 & (0) & (0) & 37 & (45) & (100) \\
\hline Tried & 6 & (17) & (40) & 9 & (24) & (60) & 0 & (0) & (0) & 15 & (18) & (100) \\
\hline Current & 1 & (3) & (3) & 20 & (54) & (65) & 10 & (100) & (32) & 31 & (37) & (100) \\
\hline Total & 36 & $(100)$ & (43) & 37 & (100) & (45) & 10 & $(100)$ & (12) & 83 & (100) & (100) \\
\hline
\end{tabular}

Robert "And you're saying now when these things [e-cigs] came out how dae they know these arenae gonnae be the same thing?"

Uncertainty was reflected in responses to questions and prompts about the health harms of e-cigarettes, with young people frequently framing these as questions, to the facilitator and each other, as the following exchange about e-cigarette content illustrates:

Finlay "They are just like a normal cigarette, really, isn't it? It's just electric. Like, you can put whatever you want in there and smoke it. It's like, people put all sorts in there, really? [...]" (15, never-smoker, never e-cigarettes)

Sara "Doesn't it just like vaporise what's in a normal cigarette?" (15, never-smoker, never e-cigarettes)

There was some discussion about whether e-cigarettes might be more or less addictive than traditional cigarettes and it was common for participants to acknowledge that they were unsure but that they would assume them to be less addictive than traditional cigarettes. Across the groups, participants offered a range of possible ingredients and chemicals that they thought e-cigarettes might contain, including: 'oils', 'flavourings', 'water', 'nicotine', 'sugar', 'liquid anti-freeze', 'tar', 'carbon monoxide', 'alcohol', 'tobacco' and other 'bad things'. Ingredients were described as producing potentially harmful 'toxins', 'poisons' and 'poisonous gases'. Despite uncertainties about the exact harms of e-cigarettes, there was general consensus that traditional cigarettes were more harmful than vaping, with vapour being "obviously not as harmful as the smoke from [a] normal cigarette" (Gerry, 14, never-smoker, never e-cigarettes).

Uncertainty and acknowledgement of lack of evidence about the harmful effects of e-cigarettes also extended to the potential effects of vapour on bystanders. Murray (16, current smoker, current e-cigarettes) mentioned: "we need to find out a bit more about, like, the chemicals that are in it to, like, know whether you'd want to be around vapers." In two groups, participants expressed concern about potential harmful chemical reactions and unknown dangers of secondhand vapour exposure.

I don't really like the idea of using e-cigarettes, smoking around me, because you don't really know what the sort of vapour that they exhale can do to you. (Alice, 17, tried-smoking, tried e-cigarettes)

[...] I think it is still unknown so I don't think it's good for people to smoke [vape] these e-cigarettes around like other people who will inhale it. (Joshua, 17, neversmoker, never e-cigarettes)

However, in most groups, participants expressed little or no concern about secondhand harms from vaping. Isaac (17, never-smoker, never e-cigarettes), for example, stated: "I think they're safe for, like, other people around you because it's not...it doesn't give the black smoke off so...that black carbon monoxide thing. It just gives out those chemical things."

All groups were asked what harms, if any, they considered might be associated with e-cigarettes. Nicotine dependency was briefly mentioned as a potential harmful effect of e-cigarette use in several groups. A key issue mentioned was that e-cigarettes could be used by established smokers to maintain their nicotine addiction in indoor spaces where traditional cigarettes were banned (see the Results section). A few participants drew comparisons of nicotine addiction to 'caffeine' addiction, and several compared nicotine harms with tobacco harms. Thomas (16, never-smoker, never e-cigarettes) postulated: "nicotine is bad for you. I know it's not as bad, I don't think it's as bad as a traditional cigarette because it doesn't have the other effects of like the blackening of your lungs and stuff. But nicotine, having too much nicotine in your blood is really bad, especially if you're having children".

Assumptions that e-cigarette use was low risk seemed to be at least partially influenced by their marketing, appearance, packaging and the absence of health warning labels and other regulation. Janice (15, neversmoker, never e-cigarettes) reflected: "Like, cigarettes with...well, I personally associated them with things like cancer, things like death, 'cause it says on a packet 'Smoking kills'. But then I kind of well think that if I saw somebody smoking an e-cigarette I'd think that was beneficial and more kind of harmless [...] e-cigarettes look, well, innocent."

\section{Appeal of e-cigarettes to children and teenagers}

E-cigarettes were described as easy to obtain, 'fun' products, with 'direct appeal' to teenagers and children due 
to the wide variety of 'great flavourings', 'bright colours' and 'fun tricks' commonly associated with them. Participants expressed particular concerns that e-cigarettes were 'inappropriate' for, yet 'attractive to children'. Several potential reasons were given for their appeal to children/young teenagers. Nine groups explicitly discussed e-cigarettes as 'a safer alternative to smoking for teenagers' and as a less harmful means of rebelling, for example:

Darnell "For people that age [14] it [e-cigs] seems to be sort of the best of both worlds. You get to sort of rebel against the teachers 'cause you're doing something they don't necessarily want you to do, but it doesn't necessarily come with the harm of a cigarette." (14, never-smoker, tried e-cigarettes)

Jane “Or as much." (17, tried-smoking, tried e-cigarettes)

Darnell "Or as much, so it's sort of a, a win-win."

In another group, participants similarly discussed e-cigarettes' appeal to young teenagers, particularly those 'scared of using proper ones', wanting to try out the experience of 'smoking' without exposing themselves to the associated harms and adult opposition:

When we were younger, like, we had fags. We used to go out to a smoker corner and smoke fags. I think now in this like generation, they've got these wee e-cigarettes. And if they see them, the parents are gonna be like, oh, as long as they dinnae smoke fags I guess it's all right. (Stewart, 17, current smoker, current e-cigarettes)

'Fitting in' and 'looking cool' were other explanations for the appeal of e-cigarettes, illustrated by the following quote and exchange:

Some people are like, they use these 'cause [...] they still wanna fit in, so they'll turn to this. [...] If a kid, a kid's trying to fit in with someone else, they're gonna look what they're doing, aren't they? If they're [others are] smoking an e, like, an electronic cigarette, they're gonna wanna do that to fit in with them, aren't they? (Finlay, 15, never-smoker, never e-cigarettes)

Rhyan "You get the younger ones who start on e-cigs, they're like smoking but they're not and they just walk around with hoods up thinking they're hard." (17, tried-smoking, tried e-cigarettes)

Katie "Gangsters wannabe." (17, tried-smoking, never e-cigarettes)

\section{Acknowledgement of e-cigarette experimentation, use and dual use among different user groups}

In 13 groups, there was consensus that the primary beneficiaries of e-cigarettes were long-term smokers, often explicitly described as 'old', 'middle-aged' and of an older generation. E-cigarettes were frequently described as benefiting 'smokers who wanted to quit'. Charity (16, never-smoker, never e-cigarettes) voiced concerns about whether e-cigarettes had lower capacity to satisfy cravings and reduce stress and therefore whether they could help smokers quit entirely: "smokers and, like, they go onto these [e-cigarettes], they might start realising that they're having no benefit off 'em an' then, like, with smoking they had more benefit, they're feeling more relaxed and less stressed, whereas with these they're just blowing in smoke and puffing it back out".

In two groups, participants with personal experience of smoking and vaping suggested that e-cigarettes could have a role in helping children and teenagers 'maintain' (Lauren, 16, never smoked, never e-cigarettes) a nicotine addiction, with participants in one group noting that e-cigarettes offered young underage smokers new opportunities to 'hide' the fact that they were smokers, while satisfying their 'cravings'. Louisa (16, current smoker, current e-cigarettes), for example, explained this to other group members: "I can use it [e-cigarette], like, in my house 'cause my mum doesn't know I smoke so then I could just use that when I'm, like, feeling like I need a fag and then the cravings just disappear so it's quite good." Similarly, Danyul (16, current smoker, current e-cigarettes) mentioned feeling "less guilty about mixing the two to up levels" (smoking and vaping to get nicotine).

Underlining their youth appeal, nine groups discussed e-cigarettes as fun products used in social contexts such as parties. Some participants considered e-cigarettes as almost exclusively 'a party thing', reporting themselves as unlikely to use them when alone. Fergus (17, current smoker, current e-cigarettes) explained how: "they're good because, like, at a party, if you're going out to a party, you never talked about fags, you just said can I get a fag? Like now people are saying, 'have you tried this flavour, have you tried this colour?' [...] it's a conversation-starter." In one group, high nicotine content e-cigarettes were deemed best because: "it makes like young people high as well 'cause, like, it gets, like, it's like the same feeling as getting drunk. A nicotine buzz" (Matthew 17, current smoker, tried ecigarettes). However, some data suggested their appeal levelled off after a while, with David (16, tried-smoking, tried e-cigarettes) reporting that e-cigarettes: "were kind of popular in my school, like about a year ago like we'd bring them to parties. [...] at that point it was seen as cool but now it's sort of seen as a joke. Everyone seems to think they're like kinda, they're a bit embarrassing really".

Building on discussions about their youth appeal, the groups were asked to reflect on whether e-cigarettes encouraged children and young teenagers to try traditional cigarettes, with seven groups discussing this as a possibility. Thus, Rhyan (17, tried-smoking, tried e-cigarettes) stated: "I think if you're not noticing the whole benefit of e-cigarettes then you probably will start going onto the harsher things. It's like the same issue with drugs-like, once you've got addicted to that kind of drug and then you realise that it's not giving you 
the type of high you're looking for, you start going onto the harder substance." Most of these discussions were speculative rather than based on experience. Only one participant, Finlay (15, never-smoker, never e-cigarettes), mentioned knowing people who had first used e-cigarettes; he drew on observations of peers who he recalled experimenting with e-cigarettes before moving to traditional cigarettes. He said: "I know a couple of people, of, like, they haven't smoked before but they've tried these on, like, a one-off basis, and then tried them again and started using them regularly, and then just moved onto, like, proper tobacco smoking and that." Contemplating whether e-cigarettes were considered an adequate substitute for and authentic alternative to, traditional cigarettes, Alex (17, current smoker, tried e-cigarettes) concluded switching would be possible either way: "smokers go from the normal cigarette to that [e-cigarette] because they're still getting the sensation of smoking a cigarette. So it would be quite easy to go the other way." Opposing such views, Lesley (17, tried-smoking, never e-cigarettes) firmly rejected the idea of e-cigarettes as a gateway, stating: "Naw, I don't think $[\ldots]$ if you started smoking e-cigarettes in the first place it'd be a bit dumb to go onto smoking cigarettes".

\section{Interplay between online and real-world experiences}

Participants identified smokers as the primary target audiences for e-cigarette marketing, but acknowledged that, because of their appeal to young people and nonsmokers, this 'intended' target group might be expanding. An issue which emerged spontaneously in six groups was the appeal of online YouTube videos showing vaping tricks, with conversations becoming good humoured as participants eagerly described particular tricks. Participants referred to the pervasiveness of these videos. For example, Caiomhe (15, never-smoker, never e-cigarettes), an avid Facebook user, said that vaping trick videos were "all I saw [on Facebook] for like, for like three weeks, that was like literally everything like I saw." Jonathan (17, never-smoker, never e-cigarettes) noted how: "The reach of those videos via social media's absolutely incredible. [...] you see people's accounts and you're like, 'Who on earth are they that they come from like the other side of the planet, they would have no idea I even exist, yet I'm watching their video."” Vaping tricks videos seemed to encourage imitation: Gregor (17, current smoker, current e-cigarettes) had tried "to make a hula hoop [using an e-cigarette] and failed." There was general ambiguity about who might be responsible for posting and promoting such videos on social media sites. Their viral nature and popularity, however, were frequently highlighted, with participants confidently stating: "You always see these cool videos of people doing them smoke tricks and I think that's how e-cigs became so popular" (Charity, 16, never-smoker, never e-cigarettes).

\section{DISCUSSION}

This focus group study provides one of the first rich descriptions of teenagers' lived experiences and perceptions of e-cigarettes. They generally viewed e-cigarettes as useful products for smokers, to quit or reduce traditional cigarette use. Although framed within considerable uncertainty, participants viewed e-cigarettes as less harmful than traditional cigarettes, believing the health risks from secondhand vapour to be lower than from traditional smoking which is consistent with current evidence. ${ }^{28}$ E-cigarettes were considered appealing to some participants since they were available in fun flavours and provided a relatively safe way to rebel. While all e-cigarette users were also smokers in our sample, teenagers' use of e-cigarettes appears to be strongly influenced by their social environments. This resonates with Corsi and Lippert's ${ }^{29}$ recent work which examines the use of e-cigarettes in US schools and suggests that some school environments facilitate e-cigarettes use. They described using e-cigarettes in a variety of situations, including at parties or, for a few smokers, when they felt they could not smoke traditional cigarettes. All of the teenagers who had used e-cigarettes had purchased them over the internet or been given them by other teenagers.

Our study adds to existing concerns about teenagers' perceptions of e-cigarettes as fun, cool products, ${ }^{30} 31$ by considering the role of marketing via (social media) channels frequently accessed by, and appealing, to this age-group. Previous research has documented the magnitude of exposure to e-cigarettes (as well as alcohol and tobacco) that occurs when viewing YouTube videos, ${ }^{32}$ and has also shown that portrayals of smoking in popular films are associated with uptake of smoking in adolescents. Our findings add to this by demonstrating the potential mechanisms by which exposure to e-cigarette materials online may influence attitudes and resultant behaviours. While restrictions on mass media marketing of e-cigarettes are increasingly considered internationally, social media and online environments are more difficult to manage because user-generated content (in particular) will not be covered by incoming regulations. Our study findings resonate with a larger US study which found that teenagers were easily able to purchase e-cigarettes from the internet because of an absence of age-verification measures used by internet vendors. $^{33}$

A key issue of focus for policy has been the potential for a 'gateway' effect to be operating. While this term has been used in varying ways, its key feature is the idea that consumption of a less risky product (such as e-cigarettes) leads to the use of a more harmful product. ${ }^{34}$ At present, there is a lack of consensus as to whether a gateway effect operates or how it could be measured. Two recent US-based longitudinal studies have suggested some adolescents may have used ecigarettes prior to cigarette smoking, ${ }^{15}{ }^{16}$ but other research has found no evidence of increased cigarette 
smoking. ${ }^{35}{ }^{36}$ It is noteworthy that all current e-cigarette users were dual users, and only one participant reported indirect evidence of e-cigarette users going on to become regular cigarette smokers. However, our study raises the possibility that an alternative effect may operate: a few of these teenagers who used e-cigarettes discussed the opportunities e-cigarettes offer to them to covertly vape (hiding nicotine intake from parents/ others). In some teenagers, this may reinforce nicotine use at a life stage when experimentation with tobacco smoking is common, which might foster the transition to regular smoking. Teenage e-cigarette users have previously noted the covert nature of e-cigarettes as a perceived advantage in a small US-based qualitative study $^{37} 38$ and in a larger questionnaire US study, authors conclude that e-cigarettes may contribute towards subsequent cigarette use via nicotine addiction or social normalisation of smoking behaviours.

\section{CONCLUSIONS}

Teenagers support e-cigarettes as smoking cessation aids for established adult smokers. They engage with these products in a different manner to traditional cigarettes. E-cigarettes are perceived as attractive to some teenagers and as offering a new product for experimentation, encouraged via online videos and social media. While we find little direct evidence of a 'gateway effect' among our participants, we identify a novel hypothesis worthy of further investigation: e-cigarettes' potential for covert use may reinforce traditional cigarette smoking in teenagers. These findings suggest policy responses should more clearly meet the needs of young people, as well as helping established adult smokers.

Acknowledgements The authors thank Josh Bain for help with data coding, Linda Bauld, Laurence Moore and Kate Hunt for commenting on the manuscript.

Contributors SH and SVK conceived of the study and initiated the study design. FT collected the data and coded it with SH, HW, HS and SVK. SH and FT conducted the analysis and $\mathrm{SH}$ prepared the initial draft of the paper. All authors contributed to redrafting, and approving the final manuscript.

Funding SH, HW, FT, HS and SVK are funded by the UK Medical Research Council as part of the MRC/CSO Social and Public Health Sciences Unit, University of Glasgow on core funding (grant number MC_UU_12017/6/ 171339-01). In addition, we received a small amount of funding for the project from Chest, Heart and Stroke Scotland, Fresh North-East and Tobacco Free Futures.

Disclaimer The funders had no influence over study design or interpretation of results.

Competing interests None declared.

Ethics approval The University of Glasgow.

Provenance and peer review Not commissioned; externally peer reviewed.

Data sharing statement No additional data are available.

Open Access This is an Open Access article distributed in accordance with the terms of the Creative Commons Attribution (CC BY 4.0) license, which permits others to distribute, remix, adapt and build upon this work, for commercial use, provided the original work is properly cited. See: http:// creativecommons.org/licenses/by/4.0/

\section{REFERENCES}

1. Yamin CK, Bitton A, Bates DW. E-cigarettes: a rapidly growing Internet phenomenon. Ann Intern Med 2010;153:607-9.

2. Yong $\mathrm{HH}$, Borland $\mathrm{R}$, Balmford $\mathrm{J}$, et al. Trends in $\mathrm{E}$-cigarette awareness, trial, and use under the different regulatory environments of Australia and the United Kingdom. Nicotine Tob Res 2015;17:1203-11

3. White J, Li J, Newcombe R, et al. Tripling use of electronic cigarettes among New Zealand adolescents between 2012 and 2014. J Adolesc Health 2015;56:522-8.

4. Wagener TL, Siegel M, Borrelli B. Electronic cigarettes: achieving a balanced perspective. Addiction 2012;107:1545-8.

5. Cobb NK, Byron MJ, Abrams DB, et al. Novel nicotine delivery systems and public health: the rise of the 'E-Cigarette'. Am J Public Health 2010;100:2340-2.

6. McKee M, Capewell S. Evidence about electronic cigarettes: a foundation built on rock or sand? BMJ 2015;351:h4863.

7. E-cigarettes: public health England's evidence-based confusion. Lancet 2015;386:829.

8. McNeill A, Brose L, Calder R, et al. E-cigarettes: an evidence update. Public Health England, 2015. https://www gov uk/ government/publications/e-cigarettes-an-evidence-update

9. Nutt DJ, Phillips LD, Balfour D, et al. Estimating the harms of nicotine-containing products using the MCDA approach. Eur Addict Res 2014;20:218-25.

10. Bullen C, Howe C, Laugesen M, et al. Electronic cigarettes for smoking cessation: a randomised controlled trial. Lancet 2013;382:1629-37.

11. Polosa R, Caponnetto P, Morjaria JB, et al. Effect of an electronic nicotine delivery device (e-Cigarette) on smoking reduction and cessation: a prospective 6-month pilot study. BMC Public Health 2011;11:786.

12. McRobbie H, Bullen C, Hartmann-Boyce J, et al. Electronic cigarettes for smoking cessation and reduction. Cochrane Database Syst Rev 2014;(12):CD010216. http://onlinelibrary.wiley.com/doi/10. 1002/14651858.CD010216.pub2/abstract

13. Flouris $A D$, Oikonomou DN. Electronic cigarettes: miracle or menace? BMJ 2010;340:c311.

14. Bell K, Keane H. Nicotine control: e-cigarettes, smoking and addiction. Int J Drug Policy 2012;23:242-7.

15. Leventhal AM, Strong DR, Kirkpatrick MG, et al. Association of electronic cigarette use with initiation of combustible tobacco product smoking in early adolescence. JAMA 2015;314:700-7.

16. Primack BA, Soneji S, Stoolmiller M, et al. Progression to traditional cigarette smoking after electronic cigarette use among us adolescents and young adults. JAMA Pediatr 2015;169:1018-23

17. Klein JD. Electronic cigarettes are another route to nicotine addiction for youth. JAMA Pediatr 2015;169:993-4.

18. Cavazos-Rehg PA, Krauss MJ, Spitznagel EL, et al. Hazards of new media: youth's exposure to tobacco ads/promotions. Nicotine Tob Res 2014;16:437-44.

19. Curry LE, Pederson LL, Stryker JE. The changing marketing of smokeless tobacco in magazine advertisements. Nicotine Tob Res 2011;13:540-7.

20. Noel JK, Rees VW, Connolly GN. Electronic cigarettes: a new 'tobacco' industry? Tob Control 2011;20:81.

21. Pepper JK, Brewer NT. Electronic nicotine delivery system (electronic cigarette) awareness, use, reactions and beliefs: a systematic review. Tob Control 2014;23:375-84.

22. Roditis ML, Halpern-Felsher B. Adolescents' perceptions of risks and benefits of conventional cigarettes, e-cigarettes, and marijuana: a qualitative analysis. $J$ Adolesc Health 2015;57:179-85.

23. Green MJ, Leyland $\mathrm{AH}$, Sweeting $\mathrm{H}$, et al. Socioeconomic position and early adolescent smoking development: evidence from the British Youth Panel Survey (1994-2008). Tob Control 2016;25:203-10.

24. Patton GC, Carlin JB, Coffey C, et al. The course of early smoking: a population-based cohort study over three years. Addiction 1998;93:1251-60.

25. ISD Scotland. SALSUS 2013-Smoking among 13 and 15-year-olds in Scotland 2013. 2014. http://www.isdscotland.org/ Health-Topics/Public-Health/Publications/2014-11-25/SALSUS 2013_Smoking_Report.pdf

26. Okoli CTC, Richardson CG, Ratner PA, et al. An examination of the smoking identities and taxonomies of smoking behaviour of youth. Tob Control 2008;17:151-8.

27. Glaser BG, Strauss AL. The constant comparative method of qualitative analysis. Soc Probl 1965;12:436-45.

28. Tobacco Advisory Group of the Royal College of Physicians. Nicotine without smoke-tobacco harm reduction. April 2016. https:// 
www.rcplondon.ac.uk/projects/outputs/nicotine-without-smoketobacco-harm-reduction-0

29. Corsi DJ, Lippert AM. An examination of the shift in school-level clustering of US adolescent electronic cigarette use and its multilevel correlates, 2011-2013. Health Place 2016;38: 30-8.

30. Choi K, Fabian L, Mottey N, et al. Young adults' favorable perceptions of snus, dissolvable tobacco products, and electronic cigarettes: findings from a focus group study. Am J Public Health 2012;102:2088-93.

31. de Andrade M, Angus K, Hastings G. Teenage perceptions of electronic cigarettes in Scottish tobacco-education school interventions: co-production and innovative engagement through a pop-up radio project. Perspect Public Health 2016;136:288-93.

32. Cranwell J, Murray R, Lewis S, et al. Adolescents' exposure to tobacco and alcohol content in YouTube music videos. Addiction 2015;110:703-11.
33. Williams RS, Derrick J, RibisI KM. Electronic cigarette sales to minors via the internet. JAMA Pediatr 2015;169:e1563.

34. Bell K, Keane H. All gates lead to smoking: the 'gateway theory', e-cigarettes and the remaking of nicotine. Soc Sci Med 2014:119:45-52.

35. Bauld L, MacKintosh AM, Ford A, et al. E-cigarette uptake amongst UK youth: experimentation, but little or no regular use in nonsmokers. Nicotine Tob Res 2016;18:102-3.

36. Eastwood B, Dockrell MJ, Arnott D, et al. Electronic cigarette use in young people in Great Britain 2013-2014. Public Health 2015;129:1150-6.

37. Peters RJ, Meshack A, Lin MT, et al. The social norms and beliefs of teenage male electronic cigarette use. J Ethn Subst Abuse 2013;12:300-7.

38. Barrington-Trimis JL, Berhane $\mathrm{K}$, Unger JB, et al. The E-cigarette social environment, E-cigarette use, and susceptibility to cigarette smoking. J Adolesc Health 2016;59:75-80. 